\title{
Mismatch negativity is not correlated with neuroendocrine indicators of catecholaminergic activity in healthy subjects
}

\author{
M. Hansenne ${ }^{1}$, E. Pinto ${ }^{2}$, G. Scantamburlo ${ }^{2}$, A. Couvreur ${ }^{2}$, J. Reggers ${ }^{2}$, S. Fuchs ${ }^{2}$, W. Pitchot $^{2}$ and M. Ansseau ${ }^{2}$ \\ ${ }^{1}$ Department of Cognitive Sciences, University of Liège, Belgium ${ }^{2}$ Department of Psychiatry, University of Liège, Belgium
}

\begin{abstract}
The identification of the brain structures and neurotransmitters responsible for the generation and/or modulation of the mismatch negativity (MMN) may contribute to a clearer understanding of its functional significance, and may have clinical implications. In this context, some findings suggest that the scalp-recorded MMN reflects activity from multiple neuronal ensembles within or in the immediate vicinity of the primary auditory cortex and with possible contribution from the frontal cortex. However, few data are available concerning the influence of neurotransmitter systems on the MMN. In this study, the relationship between both noradrenergic and dopaminergic systems and the MMN were investigated in 34 healthy volunteers. Noradrenergic and dopaminergic activities were assessed with the apomorphine and clonidine challenge tests. The results showed no significant relationship between either growth hormone $(\mathrm{GH})$ responses to apomorphine or clonidine and the MMN amplitude or latency. Therefore, this study does not demonstrate the implication of dopaminergic and noradrenergic activities as assessed by GH response to apomorphine and clonidine for the generation and/or the modulation of the MMN. However, given the complexity of the central neurotransmitter systems, these results cannot be considered as definitive evidence against a relationship between dopaminergic and noradrenergic activity and the MMN.
\end{abstract}

KEY WORDS : MMN; dopamine; noradrenaline; psychobiology; pharmacology

\section{INTRODUCTION}

The mismatch negativity (MMN) is a fronto-central component of the auditory event-related brain potential (ERP) elicited by a physically deviant auditory stimulus occurring among frequent stimuli with a latency of about $130 \mathrm{~ms}$ from stimulus onset and lasting to about 250/300 ms (Näätänen et al., 1978; Näätänen, 1990, 1995, 2001; Picton et al., 2000). The MMN is presumably generated by a mismatch process between the sensory input from a deviant stimulus and a short-term memory (sensory-memory) trace representing the physical features of the standard stimuli. This process appears to be automatic since the

MMN is elicited even by changes in unattended auditory stimuli. Therefore, the MMN is considered as a neurophysiological index of early sensory processing and automatic attention (involuntary attention) and is related to the orienting reflex (Näätänen, 1990, 1995). Few data are available concerning the influence of neurotransmitter systems on the MMN. In a single-blind placebo-controlled study, Umbricht et al. (2000) have suggested that $N$-methyl-D-aspartate receptors (NMDAR) were critically involved in the human MMN because the NMDAR antagonist keta-mine significantly decreased the peak amplitude of the MMN. These results indicated that glutamatergic activity could be involved in the genesis of the MMN. However, in a double-blind randomized placebo-controlled study, ketamine did not alter the MMN (Oranje et al., 2000). Recently, Hirvonen et al. (2000) have demonstrated that adenosine A1 and A2a receptors played a role in the generation of the MMN. Moreover, some drugs which induce reduced arousal (e.g. naltrexone and nitrous oxide) decreased the MMN amplitude (Jaaskelainen et al., 1998; Pang and Fowler, 1999), whereas some drugs which enhance memory function (e.g. vasopressin) increased the MMN amplitude (Born et al., 1998). Moreover, the attenuation of the MMN by triazolam and chlorpheniramine suggested respectively a GABAergic and a histaminergic implication in the genesis of the MMN (Serra et al., 1996; Nakagome et al., 1998).

Another way, other than psychopharmacological studies, to assess the implication of neurotransmitters in the genesis of the MMN is neuroendocrine challenge tests (Lal et al., 1972; Matussek et al., 1980; Checkley et al., 1981; Ansseau et al., 1988; Hansenne et al., 1992; Pitchot et al., 1992). In the present study, apomorphine and clonidine tests were used to assess the implication or not of the dopaminergic and the noradrenergic systems in the generation and/or the modulation of the MMN. It is reasonable to expect an association between dopaminergic activity and the MMN since both parameters are altered in psycho-pathological conditions such as schizophrenia where the impairment of the MMN is partly determined by alteration of the dopaminergic activity 
(Catts et al., 1995; Willner, 1997; Oades et al., 1997; Javitt, 2000).

\section{METHODS}

Thirty-four healthy subjects (15 women and 19 men, mean age of $28.5 \pm 9.2$ years) recruited among the staff of the University Hospital of Liège (Belgium) participated in the study. They were paid for their participation (250 Euro). They all underwent a medical interview by a physician (AC) to exclude psychiatric or somatic disorders. Moreover, all subjects had a body mass index (BMI) of between 20 and 25 (Bray, 1978; Thomas et al., 1976). The Ethical Committee of the University of Liège Medical School approved the protocol and all subjects gave their informed consent.

The MMN recording was carried out in a sound-attenuated room. The subjects were tested until a total of 150 tones was obtained after rejecting trials for eye movement or other artifacts. The auditory stimuli were presented binaurally in a random series at the rate of one trial every second. The standard stimuli were tones of $1470 \mathrm{~Hz}$, $70 \mathrm{~dB}$ and $40 \mathrm{~ms}$ duration, and the other $20 \%$ (deviant) were tones of $1470 \mathrm{~Hz}, 70 \mathrm{~dB}, 80 \mathrm{~ms}$ duration. To be sure that the subjects were distracted from the task, they were instructed to perform arithmetic operations during the experiment.

The EEG was recorded with silver-silver chloride electrodes attached at $\mathrm{Fz}, \mathrm{Cz}$ and $\mathrm{Pz}$ using linked ear-lobes for reference and right forehead for ground. All sites were cleaned with acetone and abraded to maintain a resistance below $5 \mathrm{kOhms}$. EOG was recorded from above the left eye. Amplifier gains were set at 10000, with a band pass of 0.05-35 Hz. The EEG was digitized at $250 \mathrm{sample} / \mathrm{s}$ for $900 \mathrm{~ms}$ with a $100 \mathrm{~ms}$ prestimulus baseline. Trials in which the EEG or EOG exceeded $50 \mu \mathrm{V}$ were rejected automatically.

The MMN amplitude and latency were measured as the difference in voltage between the baseline and the higher point between 150 and $260 \mathrm{~ms}$ after the stimulus onset for the difference wave where averaged ERPs to standards were subtracted from responses to deviants.

Clonidine and apomorphine tests were performed at 1 day intervals within the same week as the MMN recording, both after an overnight fast using a procedure previously described (Ansseau et al., 1988). Due to the influence of oestrogens on growth hormone secretion (Tulandi et al., 1987), only premenopausal women were included and the challenge tests were performed between days 3 and 12 of the menstrual cycle. Briefly, at 0800 $\mathrm{h}$, a butterfly needle was inserted into a forearm vein. Blood samples of $10 \mathrm{ml}$ were collected 20 min before and immediately before the injection of clonidine or apomorphine at $0830 \mathrm{~h}$. Successive blood samples were collected 20, 40, 60 and $120 \mathrm{~min}$ after the injection. Clonidine $(0.15 \mathrm{mg})$, diluted in saline to obtain $20 \mathrm{ml}$, and apomorphine $(0.5 \mathrm{mg})$, diluted in saline to obtain $0.5 \mathrm{ml}$, were injected, respectively, iv in $10 \mathrm{~min}$ and sc. Blood samples were immediately centrifuged, and plasma was frozen and kept at $-18^{\circ} \mathrm{C}$ until analysis.

Growth hormone was measured with a double antibody radioimmunoassay with intra-assay and inter-assay coefficients of variation of $13.3 \pm 4.7 \%$ and $14.8 \pm 9.6 \%$, respectively, and a detection limit of $0.1 \mathrm{mUI} / \mathrm{ml}$. Growth hormone responses to clonidine and apomorphine were assessed by the area under the curve (AUC) situated between injection ( $\mathrm{t} 0)$ and the last blood sample ( $\mathrm{t} 120)$. Both measures were performed with absolute and relative values (absolute values minus baseline). Since absolute and relative values were highly correlated $(r<0.97)$, only absolute AUC values are reported here.

The statistical analyses were performed using Statistica (4.5) for Windows (Statsoft Inc 1993). The relationships between the MMN and GH responses to clonidine and apomorphine tests were assessed by Spearman rank order correlation coefficients. 
Figure 1. Illustrative event-related potentials elicited by frequent (thin lines) and deviant tones (thick lines), and the respective potential differences (i.e. the subtracted responses, dashed lines) in two subjects
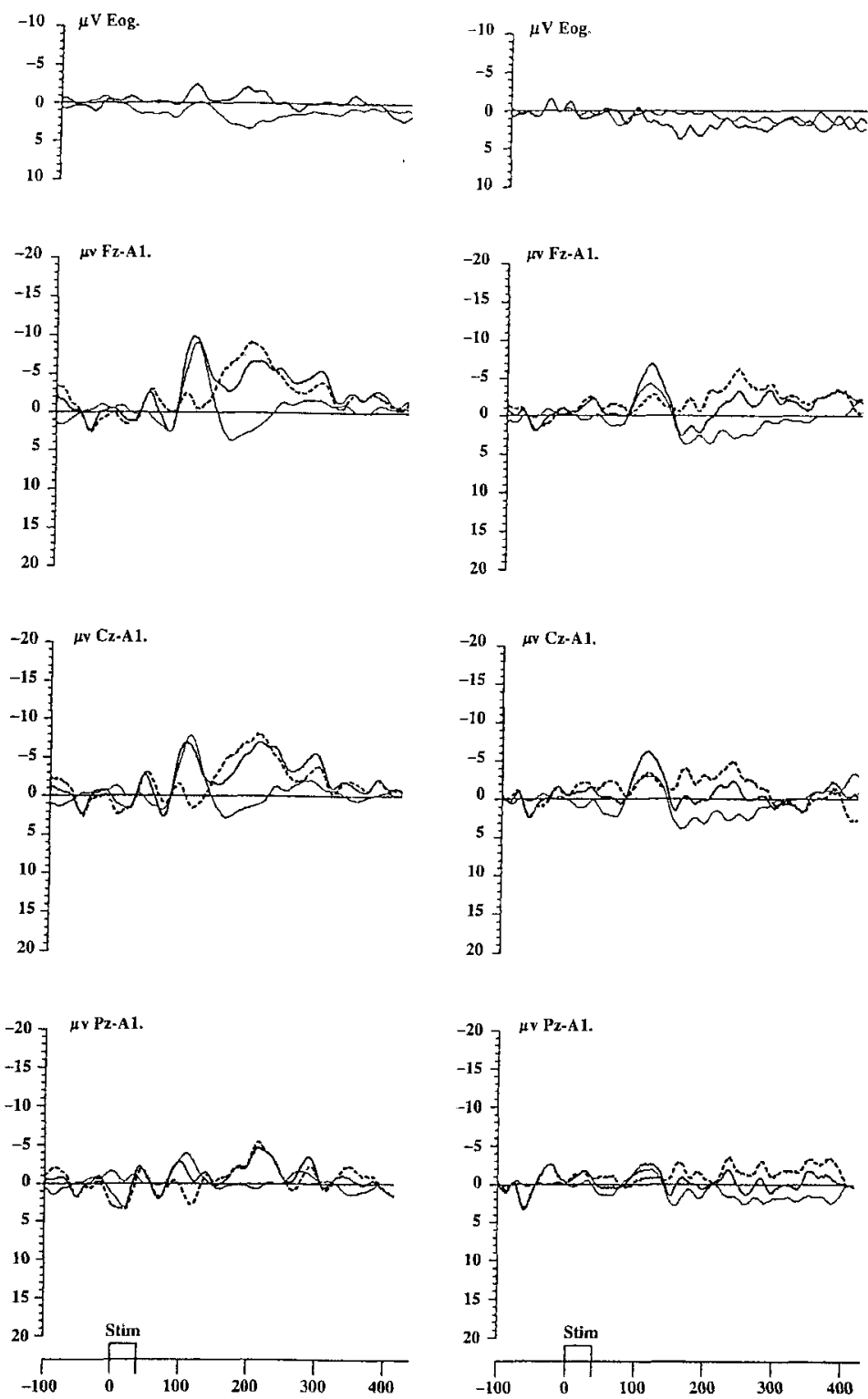

\section{RESULTS}

Figure 1 presents two illustrative ERP recordings obtained in two subjects. The mean MMN amplitude was -5.6 $\mu \mathrm{V}$ at $\mathrm{Fz}(\mathrm{SD}=2.9),-5.5 \mu \mathrm{V}$ at $\mathrm{Cz}(\mathrm{SD}=3.2)$ and $-4.5 \mu \mathrm{V}$ at $\mathrm{Pz}(\mathrm{SD}=2.8)$. Mean MMN latency was $224 \mathrm{~ms}$ at $\mathrm{Fz}(\mathrm{SD}=20.5), 222 \mathrm{~ms}$ at $\mathrm{Cz}(\mathrm{SD}=18.1)$ and $226 \mathrm{~ms}$ at $\mathrm{Pz}(\mathrm{SD}=17.6)$. Growth hormone response to apomorphine and clonidine calculated as the area under the curve (AUC) ranged respectively from 22.7 to $4638 \mathrm{IU} \mathrm{min} / \mathrm{ml}$ and from 19.2 to $4496 \mathrm{IU} \mathrm{min} / \mathrm{ml}$ with mean values of $1022.3(\mathrm{SD}=956.5)$ and $1175.8(\mathrm{SD}=$ 1128.2).

Spearman rank order correlation coefficients and probability values are presented in Table 1. No significant relationship existed between either GH responses to apomorphine or clonidine and the MMN amplitude or latency. 
Table 1. Spearman rank order correlation coefficients ( $r$ ) and probability values (p) between growth hormone $(G H)$ response to apomorphine and clonidine tests (AUC values) in 34 healthy controls

\begin{tabular}{llll}
\hline & & GH response to apomorphine & GH response to clonidine \\
\hline MMN amplitude & $\mathrm{Fz}$ & $-0.15(p=0.39)$ & $-0.01(p=0.94)$ \\
& $\mathrm{Cz}$ & $-0.16(p=0.38)$ & $0.03(p=0.87)$ \\
& $\mathrm{Pz}$ & $-0.19(p=0.27)$ & $-0.09(p=0.61)$ \\
MMN latency & $\mathrm{Fz}$ & $-0.05(p=0.79)$ & $0.27(p=0.13)$ \\
& $\mathrm{Cz}$ & $0.03(p=0.89)$ & $0.23(p=0.19)$ \\
& $\mathrm{Pz}$ & $0.01(p=0.99)$ & $0.22(p=0.21)$ \\
\hline
\end{tabular}

\section{DISCUSSION}

The results of this study did not demonstrate the implication of dopaminergic and noradrenergic activities as assessed by $\mathrm{GH}$ response to apomorphine and clonidine for the generation and/or the modulation of the MMN. However, if neuroendocrine strategy constitutes a relevant index of central neurotransmission, it exhibits limitations. Indeed, the apomorphine induces GH secretion by affecting the tuberoinfundib-ular dopaminergic system (Sourkes and Lal, 1975). Moreover, it is possible that the hypothalamo-pitui-tary GH secretory responsiveness and neocortical excitation by deviant stimuli are in fact separately regulated with regard to both dopaminergic and noradrenergic activation. In consequence, it should be noted that the study did not determine the direct effects of apomorphine and clonidine on the MMN.

A serious limitation of the study is that it can provide only limited information given the fact that the MMN recording and both apomorphine and clonidine challenges were not caried out consecutively on the same day. Indeed, there are many short-term changes in the noradrenergic and dopaminergic neurotransmissions implying that both noradrenergic and dopaminergic activities during the challenges may not be comparable to the day when the MMN was recorded. However, several lines of evidence have shown that the clonidine test may represent a stable trait and a single assessment seems to be sufficient for investigating central noradrenergic activity (Mitchell et al., 1988; Trestman et al., 1994).

In the present study, dopaminergic activity as assessed by GH response to apomorphine was not implicated in the generation and/or the modulation of the MMN. However, two reasons would have justified an association between dopaminergic activity and the MMN. The first reason is that the MMN reflects automatic attention processes and that several data suggest that dopaminergic agonists enhance attentional processes and arousal (Solanto, 1998). An association between dopaminergic activity and the MMN can reasonably postulated. A speculative explanation of the lack of an association between the MMN and dopamine is that dopaminergic activity is not implicated in automatic attentional processes but only in controlled attentional processes. In this direction, clozapine improved electrophysiological measures of controlled processes (i.e. P300 amplitude increasing), but did not ameliorate preattentive deficits (i.e. the MMN) in schizophrenic patients (Umbricht et al., 1998).

The second reason which can justify a possible association between the MMN and dopaminergic activity comes from the findings observed in schizophrenia. In fact, several studies have demonstrated that the MMN is impaired in schizophrenic patients (Catts et al., 1995; Javitt et al., 1995, 1997; Javitt, 2000), and one robust finding from biological psychiatry is a disturbed dopaminergic function in this dramatic disease (Willner, 1997). Taken together, these findings may suggest that the impairment of the MMN is partly determined by an alteration of the dopaminergic activity. Indeed, Oades et al. (1997) have suggested that impaired processing of irrelevant stimuli and reduced frontal MMN in nonparanoid schizophrenic patients could reflect reduced dopaminergic responsivity. However, no reliable neuroendocrine changes were observed in schizophrenia (Mokrani et al., 1995).

The present results did not suggest an involvement of the noradrenergic system in the genesis of the MMN. Few studies have investigated the possible implication of noradrenaline in the generation and/or the modulation of the MMN. Mervaala et al. (1993) have studied the effects of acute modulation of central noradrenergic neurotransmission on the MMN using a specific alpha-2 antagonist atipamezole in healthy volunteers. In healthy subjects, this drug produced evident noradrenergic overactivity. The results showed that atipamezole did not modulate the MMN. 
In conclusion, the present study does not suggest an association between dopaminergic and noradrenergic activities and the MMN. However, according to the restrictions mentioned above, these data are not to be considered as definitive evidence against the association between the MMN and specific neurotransmitter systems.

\section{REFERENCES}

Ansseau M, Von Frenckell R, Cerfontaine J-L, et al. 1988. Blunted response of growth hormone to clonidine and apomorphine in endogenous depression. Br J Psychiatry 153: 65-71.

Born J, Pietrowsky R. Fehn HL. 1998. Neuropsychological effects of vasopressin in healthy humans. Progr Brain Res 119: 619-1943.

Bray GA. 1978. Definition, measurement, and classification of the syndromes of obesity, Int J Obesity 2: 99-112.

Catts SV, Shelley AM, Ward PB, et al. 1995. Brain potential evidence for an auditory sensory memory deficit in schizophrenia. Am J Psychiatry 152: 213-219.

Checkley SA, Slade AP, Shur E. 1981. Growth hormone and other responses to clonidine in patients with endogenous depression. $B r J$ Psychiatry 138: 51-55.

Hansenne M, Pitchot W, Gonzalez Moreno A, Von Frenckell R, Ansseau M. 1992. Clonidine test and MMP1 scales in major depression. Eur Psychiatry 7: 129-133.

Hirvonen J, Jaaskelainen IP, Näätänen R, Sillanaukke P. 2000. Adenosine A 1/A2a receptors mediate suppression of mismatch negativity by ethanol in humans. Neuroscience Lett 278: 57-60.

Jaaskelainen IP, Hirvonen J, Kujala T, et al. 1998. Effect of naltrexone and ethanol on auditory event-related brain potentials. Alcohol 15: 105-111.

Javitt DC. 2000. Intracortical mechanisms of mismatch negativity dysfunction in schizophrenia. Audiol Neuro-Otol 5: 207-215.

Javitt DC, Doneshka P, Grochowski S, Ritter W. 1995. Impaired mismatch negativity generation reflects widespread dysfunction of working memory in schizophrenia. Arch Gen Psychiatry 52: 550-558.

Javitt DC, Grochowski S, Shelley AM, Ritter W. 1997. Impaired mismatch negativity (MMN) generation in schizophrenia as a function of stimulus deviance, probability, and interstimulus/ interdeviant interval. Electroencephalography Clin Neurophysiol 108: 143-153.

Lal S, De La Vega SE, Sourkes TL, Friesen HG. 1972. Effect of apo-morphine in human growth hormone secretion. Lancet ii: 661.

Matussek N, Ackenheil M, Hippius H, et al. 1980. Effect of clonidine on growth hormone release in psychiatric patients and controls. Psychiatry Res 2: 25-36.

Mervaala E, Alhainen K, Helkala EL, et al. 1993. Electrophysiological and neuropsychological effects of a central alpha-2 antagonist atipamezole in healthy volunteers. Behav Brain Res 55: 85-91.

Mitchell PB, Bearn JA, Corn TH, Checkley SA. 1988. Growth hormone response to clonidine after recovery in patients with endogenous depression. Br J Psychiatry 152: 34-38.

Mokrani MC, Duval F, Crocq MA, Bailey PE, Macher JP. 1995. Multihormonal responses to apomorphine in mental illness. Psychoneuroendocrinology 20: 365-375.

Näätänen R. 1990. The role of attention in auditory information processing as revealed by event-related potentials and other brain measures of cognitive function. Behav Brain Sci 13: 201-288.

Näätänen R. 1995. The mismatch negativity_A powerful tool for cognitive neuroscience. Ear Hearing 16: 6-18.

Näätänen R. 2001. The perception of speech sounds by the human brain as reflected by the mismatch negativity (MMN) and its magnetic equivalent (MMNm). Psychophysiology 38: 1-21.

Näätänen R. Gaillard AWK. Mantysalo S. 1978. Early selective-attention effect on evoked potential reinterpreted. Acta Psychol 42:313-329.

Nakagome K. Ichikawa I, Kanno O, et al. 1998. Overnight effetcs of triazomal on cognitive function: an event-related potentials study. Neuropsychobiology 38: 232-240.

Oades RD, Dittmann-Balcar A, Zerbin D, Grzella I. 1997. Impaired attention-dependent augmentation of MMN in nonparanoid vs paranoid schizophrenic patients: a comparison with obsessive-compulsive disorder and healthy subjects. Biol Psychiatry 41: 1196-1210. 
Published in: Human Psychopharmacology (2003), vol. 18, iss. 3, pp. 201-205

Status: Postprint (Author's version)

Oranje B, van Berckel BN, Kemmer C, van Ree JM, Kahn RS, Verbaten MN. 2000. The effects of a sub-anaesthetic dose of ketamine on human selective attention. Neuropsychopharmacol-ogy 22: 293-302.

Pang EW, Fowler B. 1999. Dissociation of the mismatch negativity and processing negativity attentional waveforms with nitrous oxide. Psychophysiology 36: 552-558.

Picton TW, Alain C, Otten L, Ritter W, Achim A. 2000. Mismatch negativity: different water in the same river. Audiol Neuro-Otol 5: 111139.

Pitchot W, Hansenne M, Gonzalez Moreno A, Ansseau M. 1992. Suicidal behavior and growth hormone response to apomorphine test. Biol Psychiatry 31: 1213-1219.

Serra JM, Escera C, Sanchez-Turet M, Sanchez-Sastre J, Grau C. 1996. The H1-receptor antagonist chlorpheniramine decreases the ending phase of the mismatch negativity of the human auditory event-related potentials. Neurosci Lett 203: 77-80.

Solanto MV. 1998. Neuropsychopharmacological mechanisms of stimulant drug action in attention-deficit hyperactivity disorder: a review. Behav Brain Res 94: 127-152.

Sourkes TL, Lal S. 1975. Apomorphine and its relation to dopamine in the nervous system. In Advances in Neurochemistry, Agranoff BW, Aprison MH (eds). Raven Press: New York; 247-299.

Thomas AE, McKay DA, Cutlip MB. 1976. A monograph method for assessing body weight. Am J Clin Nutr 29: 302-304.

Trestman RL, Coccaro EF, Lawrence T, Knott P, Gabriel SM, Siever LJ. 1994. The stability of plasma growth hormone and MHPG responses to repeated clonidine challenge in normal males. Psychoneuroendocrinology 19: 13-20.

Tulandi T, Lal S, Guyda H. 1987. Effect of estrogen on the growth hormone response to the alpha-adrenergic agonist in women with menopausal flushing. J Clin Endocrinol Metab 65: 6-10.

Umbricht D, Javitt D, Novak G, et al. 1998. Effects of clozapine on auditory event-related potentials in schizophrenia. Biol Psychiatry 44: 716-725.

Umbricht D, Schmid L, Roller R, Vollenweider FX, Hell D, Javitt DC. 2000. Ketamine-induced deficits in auditory and visual contextdependent processing in healthy volunteers: implications for models of cognitive deficits in schizophrenia. Arch Gen Psychiatry 57: 11391147.

Willner P. 1997. The dopamine hypothesis of schizophrenia: current status, future prospects, Int J Clin Psychopharmacol 12: 297-308. 